\title{
HAYAGUCHI KOTOBA UNTUK MELATIH PELAFALAN BAHASA JEPANG
}

\author{
Herlina Putri Handayani \\ SMK N Kesehatan dan Pariwisata Bangkinang, Kabupaten Kampar, Riau \\ herlinaputri.hp1@gmail.com
}

(Diterima: 11 Oktober 2020; Direvisi: 7 Desember 2020; Publikasi: 31 Desember 2020)

\begin{abstract}
ABSTRAK
Bahasa Jepang merupakan bahasa yang memiliki cara baca yang sama dengan tulisannya. Meskipun demikian, banyak peserta didik tidak mampu melafalkan kosakata maupun kalimat dalam bahasa Jepang dengan pelafalan yang tepat. Pelafalan dalam bahasa Jepang sangat menentukan perbedaan arti. Ketepatan dalam pelafalan sangat dibutuhkan agar menghasilkan komunikasi yang baik. Penelitian ini bertujuan untuk membiasakan peserta didik melafalkan berbagai kosakata bahasa Jepang serta meningkatkan ketepatan pelafalannya. Peserta didik menggunakan beberapa sampel hayaguchi kotoba sebagai bahan latihan. Alat yang digunakan adalah smartphone yang di dalamnya terdapat aplikasi voice recorder. Subjek penelitian ini adalah peserta didik kelas X Akomodasi Perhotelan 1 SMKN Kesehatan dan Pariwisata Bangkinang yang berjumlah 20 orang. Peserta didik terdiri dari 9 orang perempuan dan 11 orang lakilaki. Metode penelitian yang digunakan adalah penelitian tindakan kelas yang terdiri dari dua siklus di mana setiap siklus terdiri dari dua kali pertemuan. Kesimpulan yang diperoleh dari penelitian ini adalah peserta didik mulai terbiasa dengan berbagai kosakata bahasa Jepang serta ketepatan pelafalan peserta didik semakin meningkat dari siklus I ke siklus II.
\end{abstract}

Kata Kunci: Bahasa Jepang; Hayaguchi Kotoba, Pelafalan.

\begin{abstract}
Japanese is a language that the how one read is similar with how it was written. However, many students are unable to pronounce Japanese vocabulary and sentences correctly. Pronunciation in Japanese really determines the meaning of the words. Accuracy in pronunciation is required in order to produce good communication. This study aims to familiarize the students to pronounce various Japanese vocabulary as well as to improve their pronunciation accuracy. The students used several samples of hayaguchi kotoba as exercise materiasl. The devices used were smartphones with voice recorder application. This study involved 20 students of $10^{\text {th }}$ grade of Akomodasi Perhotelan 1 SMKN Kesehatan dan Pariwisata Bangkinang, consisting 9 girls and 11 boys. The research method used was a classroom action research which consisted of two cycles with two meetings in every cycle. This study concluded that the students begin to get used to various Japanese vocabulary and that their accuracy of pronunciation continues to increase from cycle I to cycle II by using hayaguchi kotoba.
\end{abstract}

Keywords: Japanese; Hayaguchi Kotoba, Pronunciation. 


\section{PENDAHULUAN}

Di dalam peraturan Direktur Jenderal Pendidikan Dasar dan Menengah Kementerian Pendidikan dan Kebudayaan nomor 07/D.D5/KK/2018 tentang struktur kurikulum terdapat mata pelajaran muatan nasional, muatan kewilayahan serta muatan peminatan kejuruan. Pada kompetensi keahlian perhotelan, bahasa Jepang adalah salah satu pilihan bahasa asing yang terdapat pada muatan peminatan kejuruan dengan alokasi waktu 144 jam. Bahasa Jepang diajarkan pada kelas X selama dua semester dengan alokasi waktu 4 jam pelajaran per minggu (Kemdikbud, 2018).

Perhotelan merupakan salah satu bidang yang erat hubungannya dengan wisatawan, baik domestik maupun mancanegara. Oleh karena itu, dibutuhkan keahlian yang baik dalam bidang komunikasi. Pelafalan merupakan salah satu aspek yang penting dalam berkomunikasi secara lisan. Mengajarkan pelafalan merupakan salah satu tantangan terbesar dalam pengajaran bahasa di lingkungan akademik apapun (Makarova, 2012). Dalam bahasa Jepang, pelafalan disebut hatsuon yang merupakan salah satu dari lima karakteristik bahasa Jepang selain kanji, kosakata, tata bahasa dan ungkapan. Pelafalan dalam bahasa Jepang sangat menentukan perbedaan arti (Renariah, 2002). Ketepatan dalam pelafalan sangat dibutuhkan agar menghasilkan komunikasi yang baik.

Berdasarkan observasi yang penulis lakukan, diperoleh hasil bahwa sebagian besar peserta didik tidak mengalami kontak langsung dengan bahasa Jepang, baik itu melalui anime, lagu maupun manga yang merupakan budaya Jepang yang terkenal di seluruh Indonesia. Dengan demikian, bisa dikatakan bahwa input peserta didik terhadap bahasa Jepang adalah nol. Sehingga mereka mengalami kesulitan dalam mengucapkan kata-kata bahasa Jepang. Meskipun tulisan dan cara baca bahasa Jepang sama, sebagian besar peserta didik tidak mampu melafalkan kosakata maupun kalimat dalam bahasa Jepang dengan pelafalan yang tepat.

Oleh karena itu, penulis memandang perlunya ada pembiasaan yang berkesinambungan untuk meningkatkan kemampuan siswa dalam pelafalan bahasa Jepang. Penulis memilih hayaguchi kotoba sebagai warming up yang akan diterapkan untuk memperbaiki pelafalan peserta didik.

Fokus penelitian ini adalah untuk pembentukan pelafalan yang baik dengan pembiasaan yang menggunakan hayaguchi kotoba. Tujuan penelitian ini adalah untuk membiasakan peserta 
didik melafalkan berbagai kosakata dalam bahasa Jepang serta untuk meningkatkan ketepatan pelafalan dalam bahasa Jepang.

Adapun manfaat dari penelitian ini adalah agar guru dapat menjadikan hayaguchi kotoba sebagai salah satu teknik yang dapat digunakan untuk melatih pelafalan peserta didik. Peserta didik memperoleh pengalaman belajar yang bermanfaat untuk meningkatkan kemampuan pelafalan dalam bahasa Jepang, serta sebagai sarana evaluasi dalam meningkatkan pelayanan pendidikan bagi siswa.

\section{KAJIAN PUSTAKA}

Beragam budaya Jepang seperti film, musik, anime, manga hingga fashion sangat populer di Indonesia (Venus \& Helmi, 2010). Banyak pemelajar yang memulai pelajaran bahasa Jepang karena tertarik dengan hal tersebut. Dengan mempertimbangkan minat peserta didik, tidak mengherankan jika banyak sekolah yang memilih bahasa Jepang sebagai bahasa asing pilihan. Hal ini sesuai dengan survei Japan Foundation (2019) yang menyatakan bahwa pada tahun 2018 tercatat sebanyak 706.603 orang pemelajar bahasa Jepang di Indonesia.

Bahasa Jepang memiliki karakteristik-karakteristik yang diklasifikasikan ke dalam lima kelompok besar yaitu hatsuon (pelafalan), moji (huruf), goi (kosakata), bunpou (tata bahasa) dan hyougen (ekspresi). Menurut pohon JF Standard, terdapat tiga jenis kemampuan berbahasa Jepang yaitu kemampuan linguistik (linguistic competence), kemampuan sosiolinguistik (sociolinguistic competence) dan kemampuan pragmatik (pragmatic competence). Kemampuan linguistik merupakan kemampuan yang sejak lama sangat diperhatikan dalam pembelajaran bahasa (Japan Foundation, 2017). Kemampuan pelafalan termasuk ke dalam salah satu jenis kemampuan linguistik selain kosakata, tata bahasa, huruf, serta penulisan.

Pelafalan adalah salah satu unsur penting dalam mempelajari bahasa apapun, termasuk bahasa Jepang. Penelitian menunjukkan bahwa berbicara merupakan elemen keahlian berkomunikasi yang paling efisien dalam pembelajaran bahasa (Brata et al., 2019). Dengan demikian, pelafalan yang baik akan membuat keahlian berbicara semakin baik sehingga dapat mencegah terjadinya kesalahpahaman arti dalam berkomunikasi.

Pengajaran hatsuon (pelafalan) lebih sulit dibandingkan aspek linguistik lainnya karena membutuhkan interaksi yang erat antara guru dan peserta didik. Interaksi tersebut akan sulit dilakukan di dalam kelas dengan jumlah peserta didik yang banyak (Makarova, 2012). Dengan keterbatasan waktu, guru harus berupaya agar mampu memperbaiki pelafalan peserta didik. 
Nakazawa (2012) dalam penelitiannya menyatakan bahwa mahasiswa merasa cemas dan takut membuat kesalahan dalam melafalkan kata-kata. Selain itu, mereka juga merasa malu untuk berbicara karena adanya kemungkinan kesalahan dalam pelafalan. Menurut Krashen (1982) salah satu kunci utama dalam pembelajaran bahasa asing adalah dengan menciptakan lingkungan yang bebas stress serta pembelajaran yang menurunkan kecemasan peserta didik. Oleh karena itu, guru hendaknya berupaya untuk menciptakan lingkungan pembelajaran yang menyenangkan, membuat peserta didik nyaman, tidak merasa tertekan serta tidak cemas dalam menghadapi pembelajaran.

Beberapa penelitian telah dilakukan untuk memperbaiki dan meningkatkan kemampuan pelafalan bahasa asing dengan cara yang menyenangkan. Mulai dari pembelajaran berbasis permainan (Makarova, 2012), pembelajaran yang menggunakan lagu (Kusrini et al., 2011), serta pembelajaran yang menggunakan kesusastraan (Leeman, 2008). Salah satu alternatif dalam mengajarkan pelafalan yang menyenangkan adalah dengan menggunakan tongue twister (pembelit lidah). Tongue twister adalah frasa atau kalimat yang sulit diucapkan karena terdiri dari banyak bunyi yang sama (Lutfiani, 2017). Tongue twister terdiri dari kombinasi suara yang sulit diatur oleh mulut dan lidah terutama bagi yang bukan penutur asli. Hal ini membuatnya menjadi alat yang berguna untuk meningkatkan pelafalan (Sitoresmi, 2016).

Mok (2014) menyatakan bahwa tongue twister (kalimat pembelit lidah) dianggap cocok sebagai latihan untuk meningkatkan pelafalan karena (1) umumnya pendek dan menyenangkan untuk diucapkan atau dibaca; (2) merupakan alat pedagogis untuk meningkatkan kesadaran fonologis dan membantu siswa berlatih suara yang sulit di bahasa target; (3) terdapat pengulangan suara yang sama, pengulangan bunyi konsonan dari kata-kata yang berurutan serta kata yang memiliki lafal yang sama namun dengan arti yang berbeda.

Sejalan dengan pendapat tersebut, Gonzalez (2009) menambahkan bahwa tongue twister adalah sebuah aktifitas yang menyenangkan untuk pembelajaran kelas bahasa apapun. Berlatih dengan tongue twister tidak hanya dapat membangun kesadaran fonemik namun juga dapat mengembangkan artikulasi dan pelafalan kata yang lebih baik (Lutfiani, 2017). Berlatih dengan menggunakan tongue twister akan menguatkan kemampuan berbicara seseorang. Semakin cepat seseorang mengucapkan tongue twister tanpa kesalahan maka semakin kuat pula kemampuan berbahasanya. 
Sebagaimana negara-negara lain, Jepang juga memiliki tongue twister yang disebut hayaguchi kotoba. Hayaguchi kotoba merupakan salah satu jenis permainan kata (kotoba asobi) yang popular di kalangan anak-anak hingga dewasa. Biasanya dimainkan untuk mengisi waktu luang atau sekadar bersenang-senang. Seiring berjalannya waktu, hayaguchi kotoba digunakan sebagai alat latihan penyiar atau pengisi suara (seiyuu) untuk membantu latihan pelafalan. Hayaguchi kotoba pun digunakan sebagai salah satu alat pembelajaran. Banyak orang Jepang yang menggunakan hayaguchi kotoba untuk mempelajari bahasa Inggris. Tetsuya (2012) menyatakan bahwa hayaguchi kotoba sangat berefek untuk membantu meingkatkan pelafalan kata-kata yang sulit diucapkan.

Hayaguchi kotoba berasal dari kata 早(hayai/haya), 口(kuchi/guchi) serta 言葉 (kotoba). Haya berarti cepat, guchi berarti mulut dan kotoba yang berarti kosakata. Dengan demikian secara harfiah, hayaguchi kotoba berarti kosakata yang diucapkan dengan cepat. Tsurumaki et al. (2011) menyatakan bahwa hayaguchi kotoba adalah permainan bahasa yang terdapat repetisi bunyi yang sama, frasa atau kalimat yang sulit dibaca, yang dilafalkan dengan cepat dan tepat.

Hayaguchi kotoba dibagi menjadi beberapa tingkatan berdasarkan tingkat kesulitan (Hosaka, 2006). Yaitu level dasar yang disebut 初級編 (shokyuuhen), level 2 yaitu tingkat menengah yang disebut 中級編 (chuukyuuhen), serta level 3 yaitu tingkat atas yang disebut 上 級編 (joukyuuhen).

Dalam penerapannya, penulis menggunakan level dasar (shokyuuhen) untuk pertemuan awal. Selanjutnya penulis mengikuti perkembangan peserta didik dengan terus meningkatkan level kesulitan hayaguchi kotoba. Hal ini dilakukan sebagai antisipasi agar peserta didik tidak jenuh. Selain itu, peningkatan kesulitan dalam pembelajaran akan merangsang peserta didik untuk terus tertantang melakukan sesuatu.

\section{METODE PENELITIAN}

Metode penelitian yang digunakan dalam penelitian ini adalah penelitian tindakan kelas. Menurut Kemmis dan Wilkinson (1998), penelitian tindakan adalah suatu bentuk penelitian refleksi diri yang dilakukan oleh para partisipan dalam situasi-situasi sosial (termasuk pendidikan) untuk memperbaiki praktik yang dilakukan sendiri. Dengan demikian, penelitian tindakan kelas merupakan suatu penelitian yang mencermati kegiatan belajar- 
mengajar dimana penelitian tersebut berkonteks kelas yang dilaksanakan oleh guru untuk memecahkan masalah-masalah yang dihadapi. Desain penelitian ini mengacu pada metode Kemmis dan Mc. Taggart yang terdiri dari 4 tahap yaitu (1) perencanaan, (2) pelaksanaan tindakan, (3) pengamatan, (4) refleksi, kemudian dilanjutkan dengan perencanaan ulang (replanning), tindakan, observasi, dan refleksi untuk siklus berikutnya, begitu seterusnya sehingga membentuk suatu spiral (Arikunto, 2010). Penelitian tindakan kelas ini terdiri dari dua siklus, setiap siklus terdiri dari dua pertemuan.

Populasi dalam penelitian tindakan kelas ini adalah peserta didik SMKN Kesehatan dan Pariwisata Bangkinang tahun ajaran 2018/2019. Sampel penelitian ini adalah kelas Akomodasi Perhotelan 1 dengan jumlah 20 peserta didik yang terdiri dari 9 orang peserta didik perempuan dan 11 orang peserta didik laki-laki.

Teknik pengumpulan data dalam penelitian tindakan kelas ini adalah dengan teknik observasi dan angket. Observasi dilakukan untuk melakukan pengamatan dan pencatatan berbagai kegiatan yang terdiri dari catatan tertulis tentang apa yang dilihat, didengar, dialami oleh peneliti untuk mengumpulkan data. Dalam hal ini peneliti mengumpulkan hasil rekaman audio hayaguchi kotoba peserta didik kemudian melakukan analisis rekaman audio tersebut. Kuesioner digunakan untuk mengetahui pendapat peserta didik mengenai penggunaan hayaguchi kotoba dalam pembelajaran.

Hayaguchi kotoba digunakan sebagai teknik warming up (pemanasan) sebelum memulai kegiatan inti pembelajaran. Warming up ini dilaksanakan selama lima belas menit dengan langkah-langkah pelaksanaan (1) Guru menampilkan kalimat hayaguchi kotoba yang akan dilafalkan bersama-sama; (2) Guru memperdengarkan cara pengucapan kalimat tersebut dengan cara membacakannya; (3) Peserta didik berlatih melafalkan kata-kata tersebut secara bersama-sama; (4) Peserta didik bertanding untuk menentukan siapa yang tercepat dan tertepat dalam melafalkan kata-kata tersebut; (5) Seluruh peserta didik berdiri saat akan melakukan pertandingan; (6) Peserta didik yang melakukan kesalahan salam pengucapan diminta untuk duduk; (7) Guru memberikan apresiasi kepada peserta didik yang telah berhasil mengucapkan hayaguchi kotoba secara cepat dan tepat; (8) Peserta didik berlatih mengucapkan salah satu dari dua pilihan hayaguchi kotoba yang telah dipersiapkan; (9) Peserta didik merekam ucapan hayaguchi kotoba dengan audio recorder.

Peneliti menggunakan instrumen hayaguchi kotoba yang berjumlah sebanyak 8 buah kalimat. Peserta didik diminta untuk mengucapkan dua buah hayaguchi kotoba untuk setiap 
kali pertemuan. Adapun hayaguchi kotoba yang digunakan dalam penelitian ini antara lain, (1) Migi mimi ni mini nikibi; (2) Maguma taishi no mama; (3) Tonari no kyaku wa yoku kaki kuu kyaku da; (4) Fukouna fuufu wa furui fuku; (5) Niwa ni wa niwatori ga niwa imashita; (6) Kaeru pyoko pyoko mi pyoko pyoko awasete pyoko pyoko mu pyoko pyoko; (7) Kono ko nakanaka katakana kakenakatta na, nakanakatta kana?; (8) Wakatta? Wakaranai? Wakattara "wakatta." to ittarai wakaranakattara "wakaranai" to iwanakattara, wakatta ka wakaranakatta ka wakaranai janai no. Wakatta?

Untuk mengukur kemampuan pengucapan peserta didik, setiap kalimat dipenggal per bagian. Setiap bagian yang pengucapannya benar diberikan 1 poin. Total skor dari setiap kalimat adalah 100 poin. Instrumen kedua yang peneliti gunakan adalah kuesioner mengenai penerapan hayaguchi kotoba di dalam pembelajaran. Kuesioner ini terdiri dari lima buah pertanyaan dengan menggunakan 4 skala likert. Setiap pertanyaan berisi pernyataan di mana peserta didik memilih antara sangat setuju, setuju, tidak setuju dan sangat tidak setuju.

\section{HASIL PENELITIAN DAN PEMBAHASAN}

Sebelum melaksanakan siklus I, peneliti melakukan persiapan pra siklus dengan mengumpulkan data yang dibutuhkan. Data tersebut adalah rekaman awal sebuah kalimat dalam bahasa Jepang. Peserta didik diminta untuk membaca kalimat "Tsukue no ue ni shashin ga arimasu". Berdasarkan data pra siklus, diperoleh hasil bahwa hanya sebesar $45 \%$ peserta didik yang tepat dalam melafalkan kalimat tersebut. Peserta didik banyak yang mengalami kesulitan saat menyebutkan huruf tsu dan sha.

Pada siklus I pertemuan 1, ketepatan pelafalan peserta didik adalah sebesar $49 \%$. Sedangkan pada siklus I pertemuan 2, ketepatan pelafalan peserta didik meningkat menjadi $64 \%$. Dengan demikian, rata-rata ketepatan pelafalan peserta didik pada siklus I adalah sebesar $56 \%$ sebagaimana dapat dilihat pada tabel 1.

Tabel 1. Persentase Ketepatan Pelafalan Peserta Didik Siklus I

\begin{tabular}{ll}
\hline Pertemuan & Persentase (\%) \\
\hline 1 & 49 \\
2 & 64 \\
\hline Rata-rata & 56 \\
\hline
\end{tabular}

Sumber: Hasil Analisis Data Penelitian (2019) 
Berdasarkan hasil rata-rata persentase ketepatan pelafalan peserta didik di siklus I menunjukkan bahwa peserta didik telah mengalami peningkatan ketepatan pelafalan dibandingkan pra siklus, yaitu sebesar 11\%. Namun demikian, siklus I masih belum menunjukkan hasil yang memuaskan.

Pada pertemuan 1, peserta didik masih mengalami kesulitan untuk melafalkan kata. Hayaguchi kotoba merupakan hal yang baru bagi mereka. Sehingga kesulitan yang mereka alami di saat pertemuan 1 merupakan hal yang wajar. Beberapa peserta didik masih malu-malu untuk melafalkan hayaguchi kotoba dengan suara nyaring. Perubahan posisi lidah yang signifikan dalam pengucapan membuat sebagian peserta didik enggan untuk melakukannya. Namun demikian, setelah diberikan motivasi peserta didik sudah mulai memiliki keinginan untuk mencoba melafalkan hayaguchi kotoba tersebut. Berdasarkan pengamatan yang dilakukan, peserta didik mengalami kesulitan dalam mengucapkan huruf shi serta reposisi lidah dari huruf $m i$ ke $n i$. Peserta didik membutuhkan waktu yang cukup untuk berlatih mengucapkan hayaguchi kotoba sehingga mereka terbiasa terhadap perubahan bunyi dan posisi lidah.

Pada pertemuan 2, peserta didik sudah mulai bisa mengatur repetisi bunyi secara perlahan. Peserta didik mulai sibuk berlatih pengucapan sendiri daripada memperhatikan mimik temannya yang sedang berlatih. Beberapa peserta didik yang awalnya malu mengucapkan hayaguchi kotoba sudah mulai terlihat melafalkannya dengan nyaring. Pada pertemuan 2, peserta didik banyak mengalami kesulitan pada perubahan bunyi huruf $k a, k i, k u$ dan kya.

Persentase ketepatan pelafalan peserta didik pada siklus II telah menunjukkan peningkatan dibandingkan siklus I sebagaimana yang dapat dilihat pada tabel 2. Pada siklus II pertemuan 1, ketepatan pelafalan peserta didik adalah sebesar 77\%. Peningkatan ketepatan pelafalan ini terus meningkat pada siklus II pertemuan 2 yaitu sebesar $84 \%$. Dengan demikian, rata-rata ketepatan pelafalan peserta didik pada siklus II adalah sebesar $80 \%$.

Tabel 2. Persentase Ketepatan Pelafalan Peserta Didik Siklus II

\begin{tabular}{ll}
\hline Pertemuan & Persentase $(\%)$ \\
\hline 1 & 77 \\
2 & 84 \\
\hline Rata-rata & 80 \\
\hline
\end{tabular}

Sumber: Hasil Analisis Data Penelitian (2019) 
Pada siklus II pertemuan 1 peserta didik menunjukkan semangatnya untuk berlatih hayaguchi kotoba. Peserta didik berlomba-lomba untuk menjadi orang yang tidak duduk selama perlombaan hayaguchi kotoba berlangsung. Selain itu, ketepatan pelafalan peserta didik menunjukkan hasil yang semakin membaik. Pelafalan bunyi yo-on (seperti bunyi huruf kya, pyo dsb) semakin membaik. Pada siklus II pertemuan 2 kondisi kelas semakin aktif. Peserta didik merasa sangat menikmati berlatih pengucapan dengan hayaguchi kotoba. Mereka merasa otot mulut mereka semakin relaks saat melafalkan kosakata. Peserta didik tertantang untuk melafalkan hayaguchi kotoba yang semakin panjang. Di sini rasa percaya diri mereka terlihat meningkat.

Secara keseluruhan persentase ketepatan pelafalan peserta didik meningkat dari pra siklus, siklus I hingga siklus II. Hal ini dapat dilihat pada tabel 3.

Tabel 3. Rekapitulasi persentase ketepatan pelafalan peserta didik

\begin{tabular}{lc}
\hline Siklus & Persentase $(\%)$ \\
\hline Pra siklus & 45 \\
Siklus I & 56 \\
Siklus II & 80 \\
\hline
\end{tabular}

Sumber: Hasil Analisis Data Penelitian (2019)

Berdasarkan tabel 3, ketepatan pelafalan peserta didik terus mengalami peningkatan di setiap tahapannya. Persentase peningkatan dari tahap pra siklus ke siklus II adalah sebesar 35\%. Selain data hasil rekaman yang telah dianalisis, peserta didik diminta untuk mengisi kuesioner. Berdasarkan hasil kuesioner yang telah dibagikan, diperoleh hasil bahwa peserta didik sangat senang berlatih pengucapan dengan menggunakan hayaguchi kotoba. Sebesar $90 \%$ peserta didik menyatakan sangat setuju bahwa pembelajaran dengan menggunakan hayaguchi kotoba adalah pembelajaran yang menyenangkan. Sementara 10\% lainnya menyatakan setuju terhadap pernyataan tersebut. Sebesar $80 \%$ peserta didik menyatakan sangat setuju, $20 \%$ peserta didik menyatakan setuju bahwa mereka mereka mulai terbiasa dengan kosakata bahasa Jepang. Selain itu, sebesar $85 \%$ peserta didik menyatakan sangat setuju, $15 \%$ menyatakan setuju bahwa rasa percaya diri mereka meningkat selama proses pembelajaran. Data selanjutnya menunjukkan bahwa sebesar $75 \%$ peserta didik menyatakan sangat setuju, $25 \%$ menyatakan setuju bahwa mereka memiliki sikap pantang menyerah. Pada pernyataan berikutnya, sebesar $80 \%$ peserta didik menyatakan sangat setuju, $20 \%$ menyatakan setuju bahwa mereka memiliki sikap berani terhadap tantangan. Untuk lebih jelasnya hal ini dapat dilihat pada tabel 4. 
Tabel 4. Persentase Kuesioner Persepsi Peserta Didik Terhadap Hayaguchi Kotoba

\begin{tabular}{lllll}
\hline \multicolumn{1}{c}{ Pernyataan } & $\begin{array}{l}\text { Sangat } \\
\text { setuju }\end{array}$ & Setuju & $\begin{array}{l}\text { Tidak } \\
\text { Setuju }\end{array}$ & $\begin{array}{l}\text { Sangat } \\
\text { tidak } \\
\text { setuju }\end{array}$ \\
\hline Pembelajaran menyenangkan & 90 & 10 & 0 & 0 \\
Terbiasa dengan kosakata Jepang & 80 & 20 & 0 & 0 \\
Rasa percaya diri meningkat & 85 & 15 & 0 & 0 \\
$\begin{array}{l}\text { Memiliki sikap pantang menyerah } \\
\begin{array}{l}\text { Memiliki sikap berani terhadap } \\
\text { tantangan }\end{array}\end{array}$ & 75 & 25 & 0 & 0 \\
\hline
\end{tabular}

Sumber: Hasil Kuesioner Data Penelitian (2019)

Peserta didik merasa pembelajaran yang diawali dengan warming up dengan menggunakan hayaguchi kotoba menciptakan suasana pembelajaran yang menyenangkan. Suasana pembelajaran di kelas berubah sehingga setiap individu di kelas berusaha untuk terus berlatih mengucapkan kata-kata sulit. Dengan kondisi seperti ini, peserta didik mulai berusaha untuk menunjukkan rasa percaya diri dan sikap berani dalam proses pembelajaran.

Hasil penelitian ini sejalan dengan penelitian terdahulu bahwa tongue twister dalam hal ini hayaguchi kotoba merupakan aktivitas yang menyenangkan dalam pembelajaran bahasa (Gonzales, 2009), meningkatkan kesadaran fonologis dan membantu siswa berlatih suara yang sulit di bahasa target (Mok, 2014) serta merupakan alat yang berguna untuk meningkatkan pelafalan (Sitoresmi, 2016).

\section{KESIMPULAN DAN SARAN}

Hasil yang dicapai dalam penggunaan hayaguchi kotoba dalam pembelajaran adalah (1) peserta didik mulai terbiasa dengan kata-kata bahasa Jepang. Meskipun belum mengetahui arti dari kata-kata yang disajikan, peserta didik tidak lagi kesulitan dalam melafalkan kata-kata maupun kalimat dalam bahasa Jepang; (2) Ketepatan pelafalan peserta didik telah meningkat. Hal ini disebabkan oleh tekunnya peserta didik berlatih untuk mengucapkan kata-kata yang sulit untuk diucapkan oleh orang Jepang sekalipun. Ditambah lagi kata-kata atau kalimat tersebut diucapkan dengan kecepatan tinggi. 
Nilai tambah yang dicapai dari pelaksanaan penelitian ini adalah (1) Menumbuhkan rasa percaya diri dalam diri peserta didik; (2) Melatih sikap pantang menyerah pada peserta didik. Meskipun lidah mereka terbelit saat mengucapkan kata-kata sulit, peserta didik tidak ada yang patah semangat. Mereka terus berlatih dengan antusias; serta (3) Menumbuhkan sikap berani terhadap tantangan.

Adapun saran penulis adalah agar guru-guru bahasa asing lain dapat menggunakan teknik ini untuk membantu peningkatan kemampuan pelafalan peserta didik dalam bahasa asing tersebut. Hendaknya guru melakukan modifikasi kata dan kalimat yang sulit sesuai dengan bahasa asing yang diajarkan.

\section{DAFTAR RUJUKAN}

Arikunto, S. (2010). Prosedur Penelitian : Suatu Pendekatan Praktik. Jakarta: Rineka Cipta.

Brata, K. C., Brata, A. H., \& Lukman, E. P. (2019). Hanasu: Interactive Japanese language mlearning application to support listening and speaking exercise. ACM International Conference Proceeding Series, December, 311-315. https://doi.org/10.1145/3345120.3345155

Gonzales, N. I. (2009). Learning English with Tongue Twister. Lulu Press Inc.

Hosaka, T. (2006). Kokoro mo Atama mo Sabi Tsukanai! Nō ga Genki ni Naru ’Puchi Torēningu’. PHP Kenkyuujo.

Japan Foundation. (2017). JF Standard bagi Pendidikan Bahasa Jepang- Petunjuk Pemakaian bagi Pengguna. The Japan Foundation.

Japan Foundation. (2019). 2018 Nen Do "Kaigai Nihongo Kyōiku Kikan Chōsa” Kekka (Sokuhō). 2018-2020.

Kemdikbud. (2018). Struktur Kurikulum Sekolah Menengah Kejuruan (SMK)/Madrasah

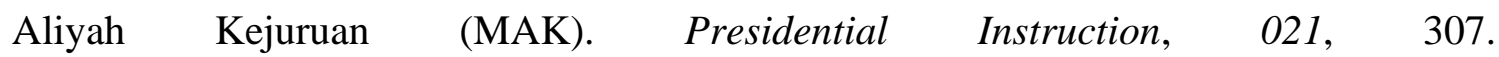
http://psmk.kemdikbud.go.id/konten/3824/struktur-kurikulum-smk-perdirjendikdasmen-no-07dd5kk2018-tanggal-7-juni-2018

Kemmis, S., \& Wilkinson, M. (1998). Participatory action research and the study of practice. Action Research in Practice: Partnerships for Social Justice in Education, 1, 21-36. 
Krashen, S. (1982). Principles and practice in second language acquisition. Oxford: Pergamon Press.

Kusrini, E., (2011). Improving English Pronunciation Through Children Songs. Aktif, 16(1), 8. .http://jurnalnasional.ump.ac.id/index.php/aktif/article/view/177

Leeman, D. G. (2008). Use of literature in teaching. Encyclopedia of Social Work with Groups, 3(September), 125-127. https://doi.org/10.4324/9780203868850

Lutfiani, D. (2017). Using Tongue Twister to Improve Students' Pronunciation. ELLITE: Journal of English Language, Literature, and Teaching, 2(2), 110-115. https://doi.org/10.32528/ellite.v2i2.1511

Makarova, V. (2012). Fun Games and Activities for Pronunciation and Phonetics Classes at Universities. 1, 1-32. papers3://publication/uuid/A0A266F4-18E4-41C4-B1F6EDFB58C6E8CE

Mok, W. E. (2014). L2 Tongue Twisters as a Diagnostic Tool for Identifying Learners' Listening and Reading Comprehension Problems. 18(1), 63-82.

Nakazawa, K. (2012). Kayo Nakazawa. NSW, Australia: Macquarie University.

Renariah. (2002). Bahasa Jepang dan karakteristiknya. Jurnal Sastra Jepang Fakultas Sastra Universitas Kristen Maranatha, 1(2), 1-16.

Sitoresmi, U. (2016). Tongue twisters in pronunciation class. Prosiding ICTTE FKIP UNS 2015, 1(1), 589-592.

Tetsuya, Y. (2012). 350 Man Hito ga Mananda Ninki Kōshi no Benkyō no Techō Eigo-Hen. Asashuppan.

Tsurumaki, Y., Yasukawa, M., \& Yokoo, H. (2011). Tongue Twister Retrieval based on Japanese Consonants. (14), 1-6.

Venus, O. A., \& Helmi, L. (2010). Budaya Populer Jepang di Indonesia: Catatan Studi Fenomenologis Tentang Konsep Diri Anggota Cosplay Party Bandung, 1, 71-90. 